BUENO, Lunielle de Brito Santos. A representação das mulheres e as discussões de gênero nas animações da Walt Disney. Domínios da Imagem, Londrina, v. 12, n. 23, p. 91-117, jul./dez. 2018.

\title{
A REPRESENTAÇÃO DAS MULHERES E AS DISCUSSÕES DE GÊNERO NAS ANIMAÇÕES DA WALT DISNEY
}

\section{THE WOMEN'S REPRESENTATION AND THE GENDER DEBATES IN WALT DISNEY'S ANIMATIONS}

Lunielle de Brito Santos Bueno•

Resumo: $\bigcirc$ presente artigo tem por objetivo compreender as representações das mulheres em duas animações da Walt Disney Animation Studios, a saber, Branca de Neve e os Sete Anões, de 1937 e Mulan, de 1998. A partir de duas narrativas distintas, em contextos sociopolíticos e de produção diferenciados, procuramos compreender quais discursos são propagados pelas narrativas fílmicas. Ademais, buscamos relacionar tais discursos com mudanças ligadas à História das Mulheres e às discussões de gênero que avançam exponencialmente desde a década de 1980 no campo historiográfico.

Palavras-chaves: Animação. Walt Disney. Representação. Gênero.

\begin{abstract}
The present article aims to understand the women's representations in two Walt Disney Animation Studios' animations. The chosen animations were Snow White and the Seven Dwarfs (1937) and Mulan (1998). From two distinct narratives, in different sociopolitical and production context, the research seeks to comprehend which discourses are propagated by film narratives. Furthermore, we seek to relate such discourses with changes linked to Women's History and the gender debates that had exponentially advance since the 1980's in the historiography.
\end{abstract}

Keywords: Animation. Walt Disney. Representation. Gender.

Quando pensamos em grandes marcos de nossas infâncias, pelo menos aos que nasceram após a década de 1970, pensamos em nosso primeiro passeio de bicicleta sem rodinhas, no brinquedo ganhado de Natal, na experiência de se ver sem dente pela primeira vez e, provavelmente, naquela ida ao cinema para ver alguma animação da Disney.

As dimensões do olhar, do olhante e do objeto a ser olhado, em nosso caso a experiência cinematográfica das animações da Walt Disney, perpassam as pesquisas de História da Arte e da chamada História Cultural

\footnotetext{
- Mestranda em História Social pela Universidade Estadual de Londrina, graduanda em Filosofia pela mesma universidade e bolsista CAPES. E-mail: Iuniellebueno@gmail.com.
} 
BUENO, Lunielle de Brito Santos. A representação das mulheres e as discussões de gênero nas animações da Walt Disney. Domínios da Imagem, Londrina, v. 12, n. 23, p. 91-117, jul./dez. 2018.

(DIDI-HUBERMAN, 2016, p. 45). As emoções humanas estão cada vez mais colocadas em perspectiva, e entender como tal dimensão auxilia na compreensão das relações sociais e das transformações culturais é uma tarefa significativa para a historiografia contemporânea.

O elemento mais fantástico do cinema é o poder de criar realidades. Não realidades historicamente vividas, mas realidades outras que carregam em si questões contextuais do momento de produção e que, sinteticamente, dão margem para a construção de um outro lugar, de um novo mundo. Isso só é possível pois o cinema não registra acontecimentos históricos do modo como eles se sucederam, ele os recria e se ele os recria, talvez seja por seu poder de tornar histórica qualquer aparição por trás de uma tela (RANCIÈRE, 2018, p. 23-31).

O cinema é uma máquina simbólica de produzir pontos de vistas e as produções fílmicas não permitem ao espectador ocupar outro ponto de vista além do vantage point que ele the prepara (AUMONT, 2004, s.p.). O olhar, neste caso, então, passa a ser construído a partir das ofertas de pontos de vista que o cinema lhe proporciona.

Partindo do incômodo de um poder inquietante que a cultura popular, principalmente o cinema, trouxe-nos, faz-se necessário compreender os mecanismos de reforço, propagação e transformação de discursos sobre o feminino. Os papeis sociais das mulheres e o próprio ser mulher é fundamental para a historiografia e para uma sociedade que, em sua grande parte, é composta por mulheres que assistiram filmes, como as animações da Disney, e que foram se estabelecendo, ou foram estabelecidas, enquanto mulheres a partir das representações apresentados por essas construções.

Objetivando compreender as representações das mulheres a partir das animações da Walt Disney, selecionamos duas, a saber, Branca de Neve e os Sete Anões (1937) e Mulan (1998), para apresentar algumas análises partindo da metodologia cinematográfica, bem como da associação das discussões de gênero tradicionais e atuais. 
BUENO, Lunielle de Brito Santos. A representação das mulheres e as discussões de gênero nas animações da Walt Disney. Domínios da Imagem, Londrina, v. 12, n. 23, p. 91-117, jul./dez. 2018.

\section{"[...] uma noiva mais que exemplar traz mais honra a todas nós" 1 : discussão de gênero, representação e metodologia cinematográfica}

Ao refletirmos sobre a História e a própria historiografia, percebemos que as mulheres, por muito tempo, foram desconsideradas enquanto sujeitos históricos. A fim de desconstruir os discursos dominantes de nossa cultura, principalmente os patriarcais, trazemos discussões que confirmam a relevância política e ética de considerar as questões de gênero como práticas culturais e sociais que legitimam, por vezes, a opressão dos corpos, dos fazeres, dos pensamentos e dos discursos.

O que é ser mulher? Será que existe um preceito universal sobre como se comportar, se vestir e agir no mundo como tal? A resposta foi dada já por Simone de Beauvoir (1980, p. 9): "Não se nasce mulher, torna-se mulher", ou seja, ser mulher não se define mais por um fator biológico; somos construídas e transformadas como qualquer indivíduo, ou seja, historicamente. Todavia, discursos dominantes de uma cultura patriarcal, tenderam e, infelizmente, ainda tendem a querer definir qual o papel da mulher no seio da sociedade.

Diante do exposto, qual a relevância de se estudar gênero? Ora, em uma sociedade que (i) traça uma atribuição desigual acerca dos espaços e papéis ocupados por homens e mulheres e (ii) constrói um discurso, de justificativa à discriminação, pautada em qualidades, traços e temperamentos diferentes (PISCITELLI, 2009, p. 118), falar sobre a mulher partindo não da perspectiva biológica de sexo, mas sob um prisma do gênero, é proporcionar uma vazão e reflexão acerca do ser mulher e às desigualdades que cercam essas agentes históricas muito desqualificadas em diversos âmbitos, inclusive no historiográfico. Mas como tais discussões se apresentam a nós na contemporaneidade? Quais os caminhos percorridos pelas mesmas?

\footnotetext{
1 Frase proferida na primeira canção do filme pela mãe e avó de Mulan.
} 
BUENO, Lunielle de Brito Santos. A representação das mulheres e as discussões de gênero nas animações da Walt Disney. Domínios da Imagem, Londrina, v. 12, n. 23, p. 91-117, jul./dez. 2018.

Votes for Women - Voto para as mulheres! Foram com essas palavras que um turbilhão de questões acerca dos papeis da mulher foram colocados em xeque no início do século XX. As sufragettes, mulheres que lutavam pelo sufrágio feminino, geraram uma série de manifestações coletivas, de cunho feminista, que foram e são referências para as discussões sociais, culturais e históricas acerca da mulher (KARAWEJCZYK, 2013, p. 1 e 2). A partir dessas manifestações, nós temos a introdução do termo gênero, pelo psicanalista Robert Stoller, em 1963. O mesmo insere nas discussões psicanalíticas o conceito de identidade de gênero para distinguir as determinações naturais e culturais, ou seja, o sexo abarcaria questões genéticas e biológicas, enquanto gênero teria relação com a cultura, desde as questões psicológicas até todo e qualquer aprendizado experienciado desde o nascimento (PISCITELLI, 2009, p. 123).

Todavia, é na década de 1970 que as formulações de gênero tiveram impacto nas teorias sociais pré-estabelecidas nas décadas anteriores. Nesse contexto, mais uma vez, o movimento feminista tem sua importância no que tange às discussões acerca de gênero, dentro e fora do campo acadêmico. Nesse período, as feministas usaram o conceito de gênero não só como uma diferenciação cultural, mas também "como uma preocupação pelas desigualdades vividas pelas mulheres" (PISCITELLI, 2009, p. 125). Disso, seguese que, a partir de uma luta social, mais uma vez, surgiu uma contribuição teórica fundamental para o pensamento social, isto é, as formulações de gênero alcançaram, aqui, um impacto na esfera do social e na teoria dos papéis sociais (PISCITELLI, 2009, p. 125).

Todavia, apesar das formulações universais e amplas do conceito, não seria inocente de nossa parte ignorar as questões de classe, étnicas, sexuais e afins que poderiam implicar diretamente nas discussões acerca das mulheres? Acreditamos que sim e, por conseguinte, pensamos gênero não com o intuito de naturalização do conceito, sem refletir sobre as questões identitárias, mas sim como um agente de intersecção com diversas modalidades de 
BUENO, Lunielle de Brito Santos. A representação das mulheres e as discussões de gênero nas animações da Walt Disney. Domínios da Imagem, Londrina, v. 12, n. 23, p. 91-117, jul./dez. 2018.

identidades constituídas discursivamente (BUTLER; TROUBLE, 1990, p. 134-139). Deste modo, há a impossibilidade de separar gênero das questões políticas e culturais nas quais é produzido e sustentado (PISCITELLI, 2002, p. 21).

De acordo com Raewyn Connell e Rebecca Pearse, pensar gênero enquanto uma estrutura em si é parte fundamental a todas pesquisadoras e pesquisadores dos estudos de gênero2. Gênero abrange corporificação social, sexualidade, relações políticas, culturais, econômicas que precisam ser compreendidas enquanto categoria que opera em um contexto, interagindo com outras dinâmicas da vida social (2015, p. 177).

Ademais, em relação aos trâmites entre as questões de gênero e a cinematografia, sabemos "que o feminino tem uma presença avassaladora no cinema desde os seus primórdios, [e] isso todos o sabemos, [...] o problema é o de saber qual o lugar que aí, no cinema, a mulher tem ocupado" (PISCITELLI, 2002, P. 21). E, se o cinema se trata de um olhar que se lança ao mundo através da grande janela que é a tela, a pergunta que nos surge é: o que ele vê, como vê e como apresenta isso através da arte?

Como bem escreveu Joan Scott,

[...] reivindicar a importância das mulheres na história significa necessariamente ir contra as definições de história e seus agentes já estabelecidos como "verdadeiros", ou pelo menos, como reflexões acuradas sobre o que aconteceu (ou teve importância) no passado. E isso é lutar contra padrões consolidados por comparações nunca estabelecidas, por pontos de vista jamais expressos como tais (SCOTT, 1992, p. 76).

Em outras palavras, faz-se cada vez mais necessário inserir as discussões acerca da importância da mulher nos processos históricos, como agente

\footnotetext{
2 Colocamos o termo "estudo de gênero" no plural pois há várias vertentes dentro do campo salientado. Raewyn Connell e Rebecca Pearse utilizam em seu livro inúmeras vezes termos em plural, uma vez que reconhecem um "estudo de gênero" norte- americano e outros menos conhecidos e difundidos como os orientais, do leste europeu e o brasileiro. Ambas propõem uma análise generalizada de gênero, um estudo que passe a abranger problemáticas e conceitos que possam ser encaixados dentro das especificidades de pesquisas de cada localidade.
} 
BUENO, Lunielle de Brito Santos. A representação das mulheres e as discussões de gênero nas animações da Walt Disney. Domínios da Imagem, Londrina, v. 12, n. 23, p. 91-117, jul./dez. 2018.

ativa, como sujeito que faz sua própria história. Todavia, seria insensato de nossa parte ignorar a outra face do fazer história, pois é extremamente importante salientar que a mulher não é só importante enquanto objeto de estudo, mas sim enquanto agente transformadora de uma historiografia que vêm reelaborando seus paradigmas, suas teorias, metodologias e suas temáticas, dando abertura para que pesquisadoras e pesquisadores possam lidar com questões como o feminino e gênero.

Diante do exposto, nossa proposta de trabalho vem amalgamar os discursos cinematográficos às as influências destes nas representações, nos imaginários ${ }^{3}$ e no reforço ou quebra de representações que envolvem as mulheres e os papeis destas, a partir das animações de uma das maiores produtoras cinematográficas, a Walt Disney Animation Studios.

Isto posto, a fim de analisarmos minuciosamente tais questões, contamos com filmes de duas fases da produtora Walt Disney, uma da fundação e a outra do final do século XX. Analisaremos duas animações, de distintas técnicas, cores, direções e roteirizações, a saber, Branca de Neve e os Sete Anões, de 1937, com aproximadamente 418 milhões de arrecadação e Mulan, de 1998, com 304 milhões.

É a partir da exibição e circulação dessas animações, que marcaram gerações distintas - e ainda vêm marcando -, que muitas ideias de representações foram difundidas e compreender quais foram essas e como elas se inserem e transformam a história é uma tarefa fundamental. Tal artigo se justifica não só pelos números estratosféricos da produtora em questão, a saber os de recepção, bilheteria, gastos com a produção, tecnologias e

\footnotetext{
${ }^{3}$ Aqui, é de suma importância colocar que compreendemos que representação nem sempre está vinculada aos imaginários. Como colocou o historiador francês Roger Chartier, o mundo como representação se dá a partir das construções sociais nas quais discursos são constituídos pelos sujeitos partindo de interesses de grupos que forjam tal representação. O imaginário social é a esfera mais profunda da relação que as questões de gênero podem causar nos indivíduos, isto é, as representações são construídas e colocadas no mundo, elas são vistas e interpretadas todos os dias. Entretanto, o toque dos imaginários, que são proporcionados pelas representações, produz forças mais complexas que, numa relação dialética, se constitui através de continuidades e rupturas importantes para o entendimento do ser mulher na sociedade.
} 
BUENO, Lunielle de Brito Santos. A representação das mulheres e as discussões de gênero nas animações da Walt Disney. Domínios da Imagem, Londrina, v. 12, n. 23, p. 91-117, jul./dez. 2018.

compras de outras empresas do ramo audiovisual, mas também pelo capital cultural (BOURDIEU, 1997) que suas superproduções têm em tocar os imaginários e as relações sociais.

A fim de trabalharmos, como objeto de pesquisa, personagens que estão inseridas em representações cinematográficas, adotamos o conceito de representação de Roger Chartier, em sua obra A história cultural: entre práticas e representações (1998), para que os processos que constroem os sentidos tanto nas fontes escolhidas, quanto na própria sociedade, sejam alvos de nossas reflexões.

O autor nos aponta que as práticas que dão o significado ao mundo são frutos de um pensamento de uma sociedade determinada, ou melhor dizendo, de um imaginário social. Com isto, o conceito de representação é utilizado para que, aplicadas às fontes, consigamos entender as formas de representação das personagens mulheres nas animações, bem como as motivações que estão entrelaçadas ao mundo social. Neste último, os atores sociais constroem discursos sobre a sociedade, de maneira a colocar seus interesses, seus anseios e suas visões de mundo. Assim, Roger Chartier escreve que

[...] as representações do mundo social assim construídas, embora aspirem à universalidade de um diagnóstico fundado na razão, são sempre determinadas pelos interesses de grupos que as forjam. Daí, para cada caso, o necessário relacionamento dos discursos proferidos com a posição de quem os utiliza. [...] As percepções do social não são de forma alguma discursos neutros: produzem estratégias e práticas (sociais, escolares, políticas) que tendem a impor uma autoridade à custa dos outros, por elas menosprezados, a legitimar um projeto reformador ou a justificar, para os próprios indivíduos, as suas escolhas e condutas (CHARTIER, 1998, p. 17).

À vista das premissas apresentadas, entendemos que os estudos de gênero devem ser cada vez mais recorrentes para uma transformação histórica sobre como a própria ciência histórica olha a mulher. Não menos 
BUENO, Lunielle de Brito Santos. A representação das mulheres e as discussões de gênero nas animações da Walt Disney. Domínios da Imagem, Londrina, v. 12, n. 23, p. 91-117, jul./dez. 2018.

importante, através da mudança interna da própria História, enquanto campo do saber, que enxerga a mulher enquanto sujeito que sofre e muda o curso da história e da historiografia, a sociedade poderá se transformar, olhar e ser olhada pelas mulheres.

Para análise das animações, o historiador deve compreender a linguagem específica dessa arte. Ao analisarmos um filme, aspectos como: o explícito e o implícito, a linguagem visual e sonora, a recepção, os condicionantes do gênero cinematográfico a qual pertence e a condição de produção e distribuição são elementos de suma importância para que a análise não se valha somente dos aspectos contextuais que são cruciais para o historiador, mas também de uma análise específica de decoupage e de análise sistematizada de elementos de composição de fontes audiovisuais (OLIVEIRA, 2008, p. 1-12).

Ratificando nossa reflexão acerca da relação de ambas as áreas, temos uma série de estudiosos contemporâneos que complexificaram as pesquisas históricas acerca do cinema. O trabalho do historiador vai além da simples compreensão do filme, pois:

[...] o filme possui um movimento que lhe é próprio, e cabe ao estudioso identificar o seu fluxo e refluxo. É importante, portanto, para que possamos apreender o sentido produzido pela obra, refazer o caminho trilhado pela narrativa e reconhecer a área a ser percorrida a fim de compreender as opções que foram feitas e as que foram deixadas de lado no decorrer de seu trajeto (MORETTIN, 2007, p. 60 e 61 ).

A partir do trecho apresentado, devemos reconhecer os filmes como uma criação humana que abrange múltiplos olhares acerca do mundo. Para retificar as premissas expostas acima, Marcos Napolitano, outro historiador que dá ênfase para as fontes audiovisuais, salienta a importância estética do cinema, uma vez que há um questionamento significativo, no qual: fazer cinema é representação, recriação e cópia da realidade ov é a automação e a construção de uma realidade outra, fantasiosa, um universo outro? 
BUENO, Lunielle de Brito Santos. A representação das mulheres e as discussões de gênero nas animações da Walt Disney. Domínios da Imagem, Londrina, v. 12, n. 23, p. 91-117, jul./dez. 2018.

Acerca dessa discussão, apontando para uma resposta sintética, na qual as produções fílmicas convergem a representação e a apresentação, e da importância dos estudos históricos sobre esse suporte, o autor afirma:

O cinema, ou o audiovisual de ficção, ocupa um estatuto intermediário entre as duas ilusões aludidas, a 'objetivista' e a 'subjetivista'. Seu caráter ficcional e sua linguagem explicitamente artística, por um lado, the conferem uma identidade de documento estético, portanto, à primeira vista, subjetivo. Sua natureza técnica, sua capacidade de registrar e, hoje em dia, de criar realidades objetivas, encenadas num outro tempo e espaço, remetem, por outro lado, a certo fetiche da objetividade e realismo, reiterado no pacto que os espectadores efetuam quando entram numa sala de cinema ou ligam um aparelho de televisão. A força das imagens, mesmo quando puramente ficcionais, tem a capacidade de criar uma "realidade" em si mesma, ainda que limitada ao mundo da ficção, da fábula encenada e filmada (NAPOLITANO, 2008, p. 236 e 237, grifo nosso).

Todavia, nas fontes em questão, temos que compreender, além da peculiaridade da metodologia fílmica, a especificidade da técnica analisada. Entendendo que animação "é uma técnica, ou melhor, um conjunto de técnicas, e não um gênero" (DENIS, 2007, p. 7), para nos ajudar na definição de gêneros cinematográficos, o Rick Altman explica que existem "bordas" e "identidades" que demarcam os diversos gêneros. Para que haja essa divisão, faz-se necessário aglutinar e sistematizar algumas características em comum que relacionem as produções. O autor escreve que cada major genre é definido a partir de quatro suposições:

(a) Cada filme foi produzido de acordo com uma reconhecida assinatura genérica (b) Cada filme exibe uma estrutura básica comumente identificada com o gênero (c) Durante a exibição cada filme é regularmente identificado por um rotulo genérico (d) A audiência sistematicamente reconhece cada filme como pertencente a um gênero em questão e consequentemente o interpreta (ALTMAN, 1999, p. 17).

Ou seja, apesar de a maioria classificar a animação como um gênero, talvez por seu apelo comercial (DENIS, 2007, p. 7), na verdade ela é um 
BUENO, Lunielle de Brito Santos. A representação das mulheres e as discussões de gênero nas animações da Walt Disney. Domínios da Imagem, Londrina, v. 12, n. 23, p. 91-117, jul./dez. 2018.

conjunto de técnicas que podem fazer filmes pertencentes aos mais diversos gêneros. Em nosso caso específico, as animações da Walt Disney classificamse como musicais com pano de fundo na categoria romance, em Branca de Neve, e aventura, em Mulan. Nas duas animações que escolhemos, há sempre uma relação amorosa que ganha foco e força durante a narrativa fílmica e, no decorrer do filme, várias músicas são apresentadas e interpretadas pelos personagens.

Mas quais seriam as especificidades dessas fontes? O que aproxima e afasta cinema de animação? Bem, a relação entre cinema e animação se estabelece a partir do entendimento que, "nascido da animação, o cinema afastou a animação para sua periferia, apenas para, por fim [o cinema digital] tornar-se um caso particular de animação" (MANOVICH, 1997, p. 302). Em outras palavras, para alguns teóricos da animação, é legítimo considerar o cinema como um tipo específico de animação (CHOLODENKO, 1991b, p. 213). Serguei Eisenstein salienta seu convencimento acerca de tal discussão entre 1940 e 1943, no que tornar-se-ia Eisenstein on Disney, quando postulou a animação como a essência do filme.

Ademais, além de compreender a animação enquanto técnica que sintetiza tanto a escrita quanto as imagens em movimento que compõem uma produção cinematográfica (kinema/kinesis e graphia), podemos também notar a construção de um espaço-tempo diferenciado, promovido pela mão humana - e hoje também pelos softwares de computadores - que não é um fazer processual de subtração e seleção ${ }^{4}$ de um recorte estabelecido pelo enquadramento da câmera, de um cenário, de uma equipe de fotografia, mas um fazer de adição, que produz espaços, personagens, temporalidades, iluminações criativamente.

\footnotetext{
4 Aqui, utilizamos os conceitos de "subtração" e "seleção" de Arlindo Machado (1984), reconhecendo-os como importantes, mesmo que para uma aplicabilidade por extensão da fotografia para o cinema, assim como da pintura para a animação.
} 
BUENO, Lunielle de Brito Santos. A representação das mulheres e as discussões de gênero nas animações da Walt Disney. Domínios da Imagem, Londrina, v. 12, n. 23, p. 91-117, jul./dez. 2018.

"No reino da ilusão onde constantemente se move [o animador], pode recriar à sua vontade o caos dos firmamentos ou a décima milionésima parte do inseto mais minúsculo" (MARTIN, 2000, p. 396). Por conseguinte, podemos perceber que uma característica fundamental da animação é, além de poder transitar livremente entre o micro e o macro do processo criativo sem intervenção das impossibilidades físicas ou dos efeitos especiais - que pode ser considerado como uma técnica de animação dentro dos filmes que não são completamente animados (DENIS, 2007, p.11) -, a de poder dar vida a uma matéria totalmente inerte (MOINS, 2001, p. 128).

\section{"Se me deixarem ficar eu tomo conta de tudo, eu lavo, varro, costuro, cozinho...": A passividade de Branca de Neve (1937)}

A primeira animação da Walt Disney Animation Studios foi Branca de Neve e os Sete Anões, lançada em 1937 nos Estados Unidos. Segundo o Guinness World Records, de 2018, com as correções inflacionárias, teria arrecadado o equivalente a 1,2 bilhão de dólares em 10 de maio de 2018, alçando assim mais uma conquista, além de ter sido o primeiro filme com trilha sonora oficial (GUINNESS, 2018, p.182).

Foi dirigida por David Hand, conta com a roteirização de Dorothy Ann Blank, Richard Creedon, Merrill De Maris, Ted Sears, Otto Englander, Earl Hurd, Dick Rickard e Webb Smith, do conto dos irmãos Grimm, Snow White, de 1812. O longa-metragem, produzido nos moldes das animações tradicionais, conta a história de um embate feminino representado por duas categorias de personagens, a saber, a mocinha heroína, Branca de Neve e a madrasta má, Rainha Grimhilde.

Logo no início do filme, enquanto o narrador conta o contexto em que se passa a história, podemos levantar características de ambas as personagens, induzidas pelo próprio narrador quando diz "a vaidosa e malvada madrasta, a rainha, cobriu a princesinha de andrajos e obrigou-a a 
BUENO, Lunielle de Brito Santos. A representação das mulheres e as discussões de gênero nas animações da Walt Disney. Domínios da Imagem, Londrina, v. 12, n. 23, p. 91-117, jul./dez. 2018.

trabalhar como criada" e "Branca de Neve ficou livre da inveja e crueldade da rainha enquanto o espelho respondia que ela era a mais bela".

Destarte, podemos salientar que a disputa entre ambas não é de poderio político, nem de poderio econômico, mas sim uma disputa de beleza, na qual a Rainha é colocada como vaidosa, malvada, invejosa e cruel diante da mocinha, princesinha e injustiçada Branca de Neve.

No decorrer dos diálogos do filme, há diversas falas negativando a Rainha e reafirmando sua vilania, a saber, "ela é invejosa, ninguém pode detê-la", "é perversa, é perigosa, é uma feiticeira", "[a Rainha] virá voando para cá! Ela sabe de tudo e faz bruxarias, pode até se tornar invisível" e "a Rainha é perigosa, é uma bruxa!". Todas essas frases, com exceção da primeira que é do caçador, foram ditas pelos anões, que, sempre que se referiam à Branca de Neve, com exceção do Zangado, mostram-se totalmente antagônicas quando comparadas com as sobre a Rainha.

A caracterização da personagem Rainha, sem sombra de dúvidas, utiliza não só da paleta de cores e dos diálogos, mas até mesmo da escolha da atriz para interpretar a voz, como também o gestual apresentado pelos animadores.

As cores associadas à Rainha, são vermelho, roxo, preto e dourado, apresentando um figurino muito utilizado nos anos 30 para caracterização de rainhas da época medieval5. Seu trono é um pavão dourado, com toques azulados, com um brasão embaixo que só é possível ver o símbolo da realeza (dois sois em diagonal) e uma serpente em destaque, mostrando, também, não só sua imponência, mas como a sua maledicência, sua vilania, seu poderio autoritário.

\footnotetext{
5 Um dos exemplos emblemáticos é o figurino da personagem Rainha Ayesha, do filme She
} (1935). 
BUENO, Lunielle de Brito Santos. A representação das mulheres e as discussões de gênero nas animações da Walt Disney. Domínios da Imagem, Londrina, v. 12, n. 23, p. 91-117, jul./dez. 2018.

Figura 1: Vestuária da Rainha Má/Madrasta

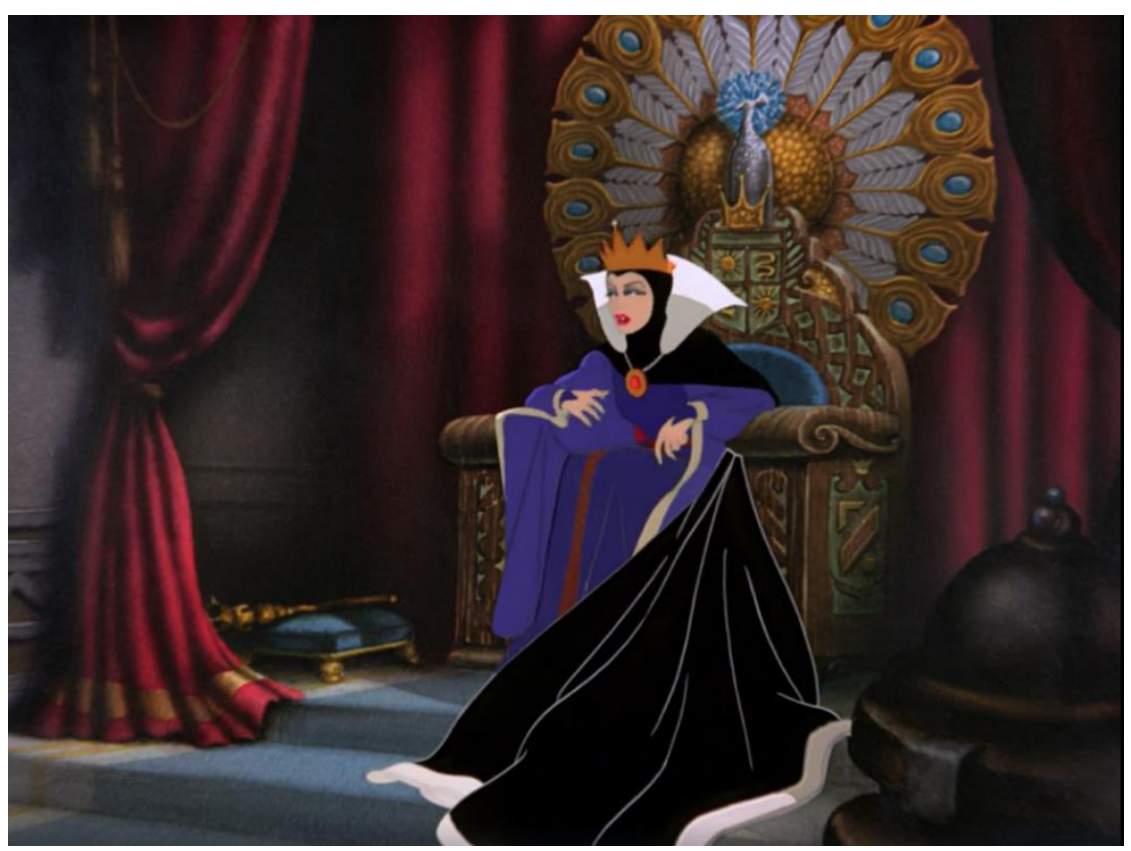

Fonte: Branca de Neve e os Sete Anões (1937), 7 m09s

A atriz que faz a voz da Rainha Grimhilde é Lucille La Verne, o marco de sua voz não é exatamente o timbre ou o alcance vocal, mas a interpretação que ela dá a partir de suas falas, principalmente quando fala com o Espelho Mágico e quando se transforma na Bruxa e solta uma gargalhada.

Ainda no que tange à vilã da história, quando a mesma usa de artifícios mágicos como alquimia e bruxaria para se transformar numa "velha mendiga" e enganar Branca de Neve e fazê-la ser envenenada, suas vestes tornam-se todas pretas, seu belo corpo torna-se velho, enrugado, com uma verruga no nariz, corcunda e sua voz tem como característica a rouquidão. 
BUENO, Lunielle de Brito Santos. A representação das mulheres e as discussões de gênero nas animações da Walt Disney. Domínios da Imagem, Londrina, v. 12, n. 23, p. 91-117, jul./dez. 2018.

Figura 2: Vestuário da bruxa
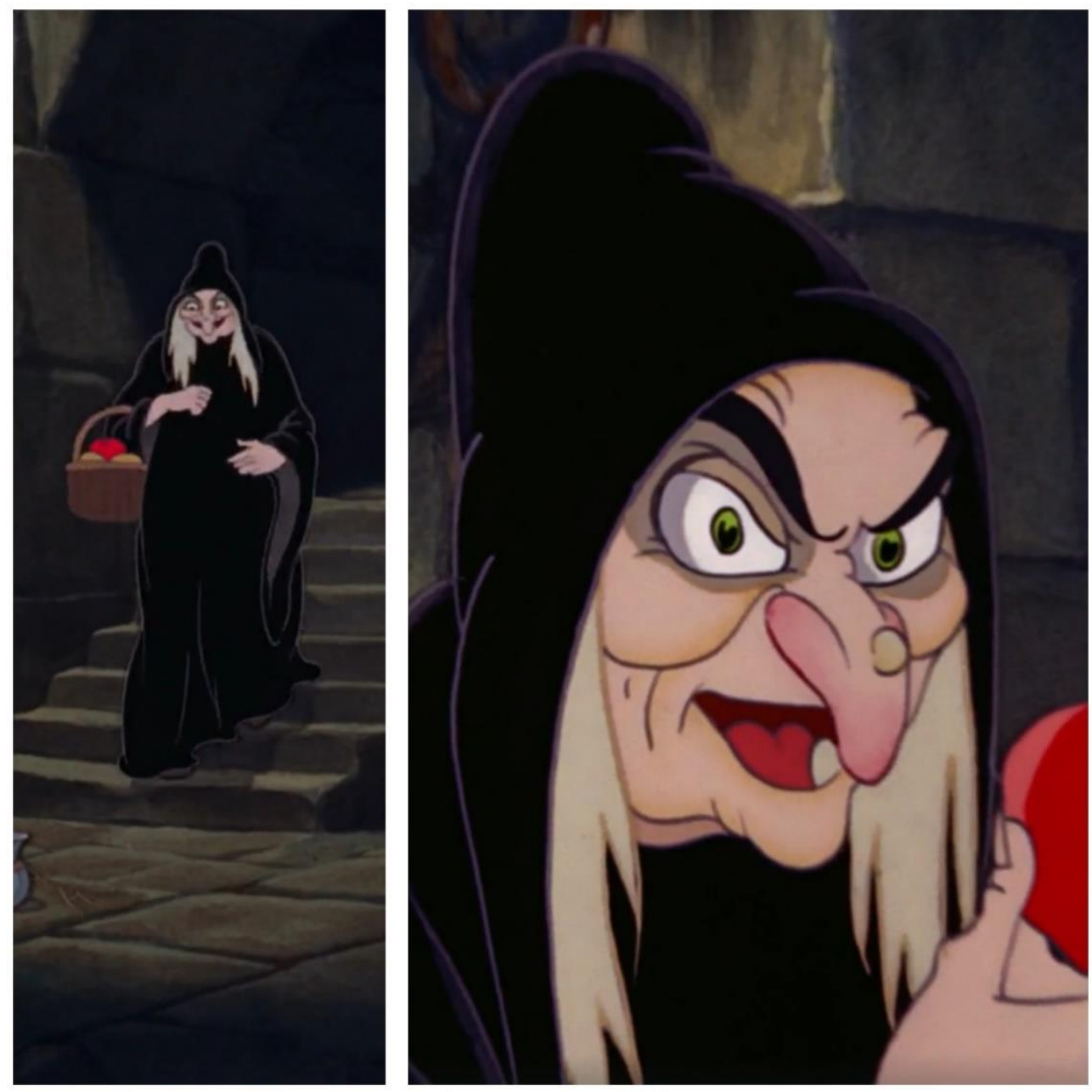

Fonte: Branca de Neve e os Sete Anões (1937); À esquerda 64m40s, à direita 63m15s

É importante salientar que a Rainha, na condição de vilã e madrasta má do conto de fada, é representada como uma mulher madura, poderosa 
BUENO, Lunielle de Brito Santos. A representação das mulheres e as discussões de gênero nas animações da Walt Disney. Domínios da Imagem, Londrina, v. 12, n. 23, p. 91-117, jul./dez. 2018.

e independente. Porém, compartilha o mesmo destino que as outras vilãs do mundo Disney: a auto destruição. Isto é, a narrativa é construída a fim de que suas próprias ações maléficas voltem contra si próprias. Especificamente em Branca de Neve e os Sete Anões, a Rainha cai de um penhasco e morre.

Já a mocinha, Branca de Neve, pode ser caracterizada como o total oposto de sua madrasta. Sua voz, interpretada por Adriana Caselotti, é o que costumamos caracterizar como virtuosíssima, sua extensão vocal é de uma soprano, transformando as canções num verdadeiro espetáculo musical dentro das telas do cinema.

Suas vestes, num primeiro momento, são rasgadas, remendadas, com tonalidades de branco, preto, chumbo, cinza e bege. Dessa roupa, o que mais me chama a atenção são os sapatos holandeses de madeira que Branca de Neve usa. Na verdade, esse primeiro figurino possui, também, referência à época medieval. O nome do sapato é clog, e sua principal característica é ser feito de madeira, e o de Branca de Neve é similar aos sabots franceses e klomps holandeses, de uma mesma ascendência, provavelmente.

Figura 3: Vestuário Branca de Neve 
BUENO, Lunielle de Brito Santos. A representação das mulheres e as discussões de gênero nas animações da Walt Disney. Domínios da Imagem, Londrina, v. 12, n. 23, p. 91-117, jul./dez. 2018.

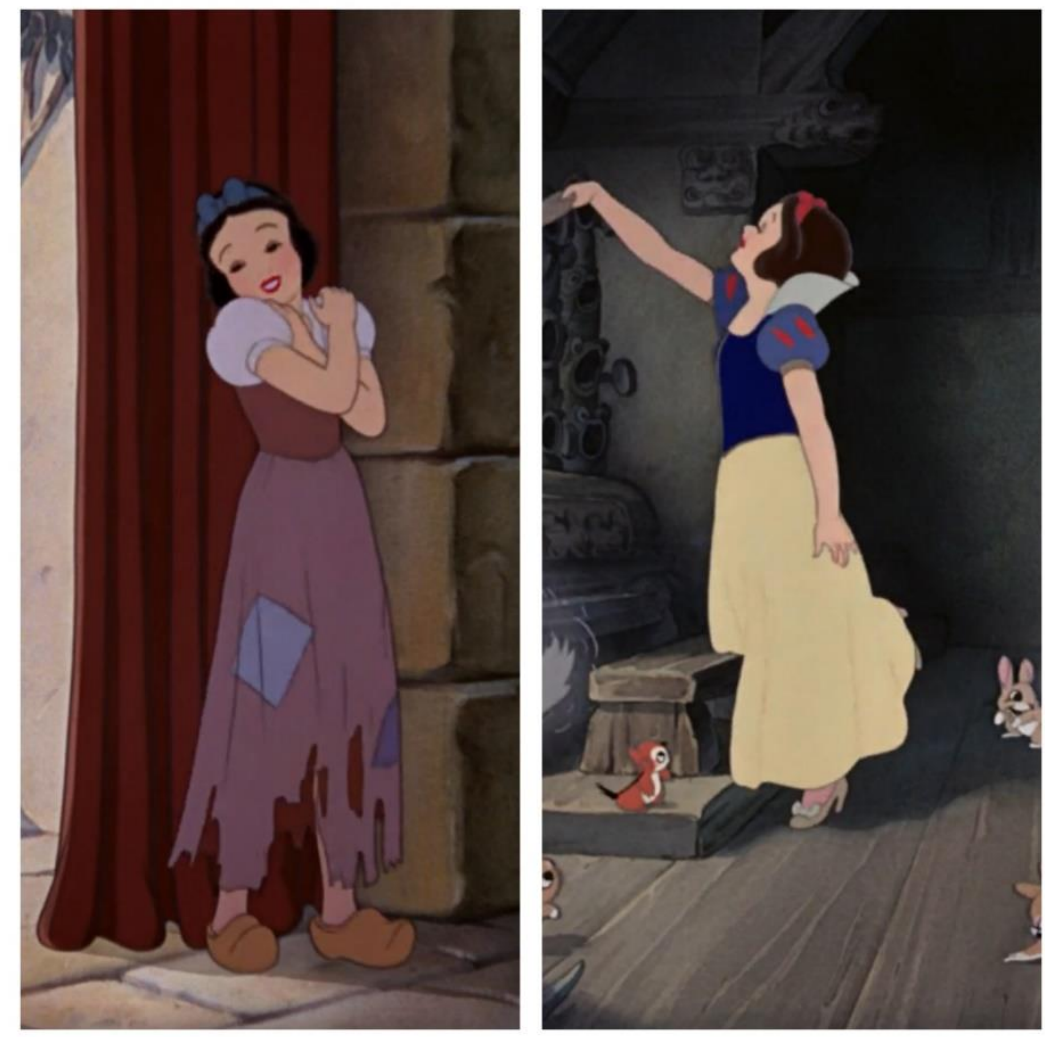

Fonte: Branca de Neve e os Sete Anões (1937). À esquerda 5m59s, à direita 19m16s.

Já o segundo figurino, à direita na figura 3, é muito inspirado nos anos 30, tanto o sapato amarelo com laço à frente quanto as mangas "bufantes" de seu vestido de princesa. Desta segunda roupa é extremamente interessante notar a escolha dos coloristas para a paleta de cores: azul, vermelho, branco e amarelo, quase as mesmas cores das roupas do príncipe que já aparecem no primeiro arco do filme. Tal escolha nos mostra o interesse de harmonização dos personagens, que voltam a se encontrar no terceiro arco, quando o príncipe salva Branca de Neve, não só pela realeza, mas principalmente pelo romance.

Figura 4: Combinação de vestimentas 
BUENO, Lunielle de Brito Santos. A representação das mulheres e as discussões de gênero nas animações da Walt Disney. Domínios da Imagem, Londrina, v. 12, n. 23, p. 91-117, jul./dez. 2018.

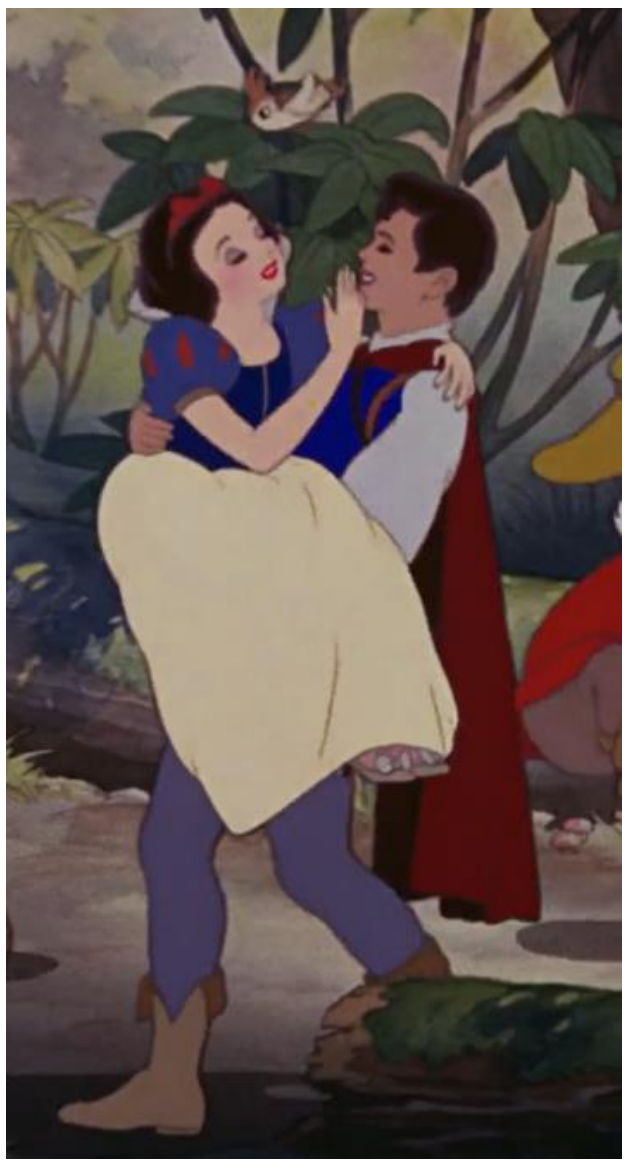

Fonte: Branca de Neve e os Sete Anões (1937), $71 \mathrm{~m} 31 \mathrm{~s}$

É interessante notar que o enredo em que Branca de Neve se insere tornou-se um marco na Era de Ouro ${ }^{6}$ da Disney: uma menina, órfã de mãe, que desde a tenra infância fica à mercê de uma mulher mais velha e má que exerce autoridade sobre sua vida (DAVIS, 2015, p. 100 e101). Pois há um pai ausente, ou já falecido, que a força, indiretamente, a entrar na jornada que a leva a amadurecer. Tal estrutura narrativa é bastante comum no folclore e nos contos da Europa Ocidental (DAVIS, 2015, p. 103).

6 A Golden Age da Walt Disney Animation Studios pode ser caracterizada pelo estabelecimento da Disney como pioneira no ramo das animações e coincide com as produções que foram feitas durante a vida de Walt Disney. Essas vão de Snow White and the Seven Dwarfs, de 1937, até The Jungle Book, de 1966. Outros dividem este mesmo período em três fases, explicada pela descontinuidade do ápice das produções: The Golden Age, dos anos 1937 a 1942, The Wartime Era, de 1943 a 1949, e The Silver Age, dos anos 1950 a 1966. 
BUENO, Lunielle de Brito Santos. A representação das mulheres e as discussões de gênero nas animações da Walt Disney. Domínios da Imagem, Londrina, v. 12, n. 23, p. 91-117, jul./dez. 2018.

A figura da madrasta, aqui, não é somente aquela que maltrata a heroína e usurpa seu espaço político e social, mas é aquela que faz o possível para oprimir a garota e afastá-la de encontrar o amor verdadeiro, o qual é ansiado por Branca de Neve e evidenciado por quase todas as canções que a mesma entoa.

Quando paramos para analisar as letras das canções cantadas por Branca de Neve, como "o sonho que eu sonhei, há de acontecer. O castelo que eu imaginei de verdade um dia há de ser. Meu eterno amor um dia encontrarei [...]", percebemos o forte apelo na condição de "sonho de princesa" que é reafirmado aqui. Sonhe com castelos, com um príncipe encantado, com um final feliz e ele se tornará realidade.

Ademais, é importante ressaltar que, em nenhum momento da narrativa fílmica, há o incentivo da protagonista às suas espectadoras, aquelas que, possivelmente, são as mais tocadas em seus imaginários, em correr atrás de seus sonhos. Ela foge de vergonha do príncipe, ela não enfrenta a madrasta e ela não enfrenta o caçador, sua condição é de total passividade dentro das intempéries da vida e, mesmo passando pelos diversos obstáculos passivamente, com seu jeito dócil e meigo, ela, ainda assim, consegue ter o final feliz.

Ainda sobre sua condição de passividade, a condição que ela se coloca diante dos anões também nos mostra, indiretamente, a visão que a própria protagonista passa a ter do "papel da mulher". Como moeda de troca em poder ficar na casa dos anões, ela fala "se me deixarem ficar eu tomo conta de tudo, eu lavo, varro, costuro, cozinho...". Tais afazeres, por muito tempo, e ainda nos dias atuais nas famílias tradicionais, são colocados como funções femininas a serem desempenhadas no âmbito que as mesmas devem habitar, isto é, o privado.

Aqui temos uma interessante comparação: a Rainha, mais velha, mais poderosa, vinculada à bruxaria e má é da esfera pública e política, já Branca 
BUENO, Lunielle de Brito Santos. A representação das mulheres e as discussões de gênero nas animações da Walt Disney. Domínios da Imagem, Londrina, v. 12, n. 23, p. 91-117, jul./dez. 2018.

de Neve, mais jovem, indefesa, cristã $\tilde{7}^{7}$ e dócil é da esfera privada, do lar. Isto posto, podemos perceber que as associações feitas à mulher poderosa são negativadas, não sendo um bom exemplo do "ser mulher". Disso decorre que todas as investidas de Zangado contra Branca de Neve no decorrer dos diálogos, são sempre associadas à maldade das mulheres, a mesma que é associada à Rainha, como "os feitiços dela já começaram, já vou avisando, se cederem um pouco, ela toma conta de todos vocês" e "ela é uma mulher e as mulheres são falsas, cheias de sortilégio".

\section{"Assustadas, em fileira, vamos à casamenteira": A boa filha Mulan (1998)}

Mulan, animação de 1998, foi dirigida por Tony Bancroft e Barry Cook, produzida por Pam Coats e roteirizada por Rita Hsiao, Chris Sanders, Philip LaZebnik, Raymond Singer e Eugenia Bostwick-Singer. A personagem a ser analisada é Fa Mulan, dublada por Ming-Na, e tem sua inspiração na lenda chinesa de Hua Mulan e na adaptação de Robert D. San Souci, Fa Mulan: The Story of a Woman Warrior, lançada no mesmo ano de lançamento da animação.

A primeira aparição de Mulan no filme se dá quando a mesma começa a escrever em seu braço uma cola das características de uma boa noiva. "Calma e reservada, graciosa e educada, delicada, refinada, equilibrada... Pontual!" Entretanto, Mulan apresenta outras características que, sob qualquer olhar, não são ruins, como "boa, honesta, inteligente, de bom coração e bom senso de justiça, franca" (DAVIS, 2015, p. 195).

O que há de conflituoso, então, entre as características de uma boa noiva e as apresentadas por Mulan? Muitos estudos de gênero apontam que a esposa ideal não teria como características principais a inteligência ou o

\footnotetext{
7 Tal comparação entre bruxaria e cristianismo se dá pela conotação negativa que os demais personagens dão ao chamar a Rainha de bruxa. No que tange à afirmação de que Branca de Neve seria cristã, pautamos tal premissa na sequência em que a mesma, ajoelhada olhando para cima, pede para abençoar os anões e realizar seus sonhos e, no final, ela diz "amém".
} 
BUENO, Lunielle de Brito Santos. A representação das mulheres e as discussões de gênero nas animações da Walt Disney. Domínios da Imagem, Londrina, v. 12, n. 23, p. 91-117, jul./dez. 2018.

senso de justiça, pois poderiam causar conflitos em seus matrimônios. Isso se deve ao fato de existir dentro da lógica das relações de gênero, no patriarcado, uma divisão social do trabalho no qual a mulher deveria cuidar da casa e dos filhos. Para tal, ser calma e reservada para com seu marido, graciosa e educada para ensinar seus filhos, delicada, refinada, equilibrada e pontual para estabelecer as relações sociais privadas da família é ser uma "boa mulher" (PISCITELLI, 2009, p.137-139).

Durante o primeiro arco do filme, há toda uma investida da família Fa para que Mulan seja bem sucedida em seu teste de "boa noiva" com a casamenteira. Seu pai diz "contamos com você para honrar nossa família", sua mãe e avó cantam "uma noiva mais que exemplar traz mais honra a todas nós" e "a moça vai trazer a grande honra ao seu lar, achando um bom par e com ele se casar". A pressão familiar para que Mulan se case é tão grande que a mesma, atuando no papel de "boa filha" - e essa característica a acompanhará até o fim da narrativa fílmica - convence-se, submersa na lógica tradicional da sociedade chinesa, de que só conseguirá dar honra a família sendo aprovada pela casamenteira.

Essa primeira canção, cantada por sua mãe e avó e pela própria Mulan e as outras noivas, sem sombra de dúvidas, é quase um tratado da mulher ideal dentro de uma sociedade patriarcal. O que difere os momentos das canções entre Mulan e sua mãe e avó é que Mulan deixa claro que está tentando honrar seu pai no trecho "ancestrais, ouçam bem, eu vos peço proteção também, para que encontre logo um alguém e ao meu pai eu vou honrar". Já sua mãe e avó, além dos trechos apresentados acima, dão certas dicas a Mulan, como "mas terá que ser bem calma, obediente e ter vigor, com bons modos e com muito amor". Portanto, podemos perceber a diferença de pensamento e de motivação volitiva das ações de Mulan e das mulheres de sua família.

Ainda no que tange a tal canção, um dos momentos-chave, quando o assunto é o sentimento das candidatas, é a frase entoada por todas, 
BUENO, Lunielle de Brito Santos. A representação das mulheres e as discussões de gênero nas animações da Walt Disney. Domínios da Imagem, Londrina, v. 12, n. 23, p. 91-117, jul./dez. 2018.

"assustadas, em fileira, vamos à casamenteira". A palavra "assustadas" mostra-nos que, além de Mulan, todas as outras candidatas não se sentem à vontade em participar de tal processo, cumprindo-o somente pela imposição social e/ou familiar.

Após o mal sucedido encontro com a casamenteira, Mulan entoa uma nova canção dizendo que "a perfeita esposa jamais vou ser, ou perfeita filha [...] talvez tenha que me transformar", desistindo de suas características por não se encaixar no padrão de boa noiva, encerrando o primeiro arco do filme descontente com sua falta de habilidades de uma boa esposa ou boa filha. É importante destacar que muito desse estigma do que uma boa esposa ou uma boa filha deve ter diante das figuras masculinas de sua vida ainda é patente em nossa sociedade. Muitos homens preparam e são preparados a esperar certas condutas de suas esposas ou filhas, atribuindo certos papeis que deveriam ser cumpridos exclusivamente por elas, como se o "ser mulher", naturalmente, englobasse esses papeis.

É importante destacar certas falas dirigida a Mulan durante o decorrer na narrativa fílmica, pois essas demarcam, mesmo no fim do século XX, um certo estigma colocado sobre as mulheres, de modo geral. "Seria bom ensinar sua filha a dobrar a língua na presença de um homem" (Chi-Fu), "Mulan, isso é uma desonra!" (pai de Mulan envergonhado da atitude da filha ao contestar Chi-Fu), "Víbora, traiçoeira!" (Chi-Fu), "É uma mulher, nunca será digna de nada" (Chi-Fu) e "Ela traz pra casa uma espada. Deveria ter trazido um homem maravilhoso" (avó de Mulan, após ela voltar da guerra com honrarias dadas pelo próprio imperador chinês).

A partir das frases acima, podemos perceber que, mesmo as mulheres que cercam Mulan, disseminam ideias de cunho machistas como a honra de ter trazido a espada imperial para casa não ser suficiente, quando comparada a de arrumar um marido. Todavia, algo interessante em se notar, são os próprios estigmas colocados sobre os homens, inclusive pela própria Mulan, como "não é porque me pareço com um homem que eu tenho que 
BUENO, Lunielle de Brito Santos. A representação das mulheres e as discussões de gênero nas animações da Walt Disney. Domínios da Imagem, Londrina, v. 12, n. 23, p. 91-117, jul./dez. 2018.

cheirar como um", mostrando, assim, que o filme, apesar de ser o primeiro da Disney a discutir, implicitamente, papeis sociais de mulheres e homens, também reforça certos estereótipos sobre os agentes envolvidos nas questões de gênero.

As cores colocadas para representação da personagem nos momentos distintos da narrativa são bastante relevantes quando pensamos sobre a caracterização de feminilidade. Num primeiro momento, Mulan usa uma bermuda e blusa azuis; quando vai à casamenteira, vai com um kimono rosa, bordô e laços azuis marcando, não só pelas roupas e maquiagem, mas pelas cores, uma busca de feminilidade. Como Ping (seu nome falso como soldado) veste roupas pretas e verdes e no final, quando finalmente torna-se o que realmente queria ser (DAVIS, 2015, p. 198-199), Mulan usa uma veste que parece um kimono, nas mesmas cores que da vestimenta que usou ao ir à casamenteira, mas o kimono é azul e os laços são rosa, invertendo a ordem da vestimenta de noiva, sem maquiagem e de cabelos soltos. Isto posto, podemos notar que, para além da evolução da personagem no roteiro, há uma marcação de mudança da personagem através das cores das roupas.

Figura 5: Vestimentas de Mulan/Ping 
BUENO, Lunielle de Brito Santos. A representação das mulheres e as discussões de gênero nas animações da Walt Disney. Domínios da Imagem, Londrina, v. 12, n. 23, p. 91-117, jul./dez. 2018.
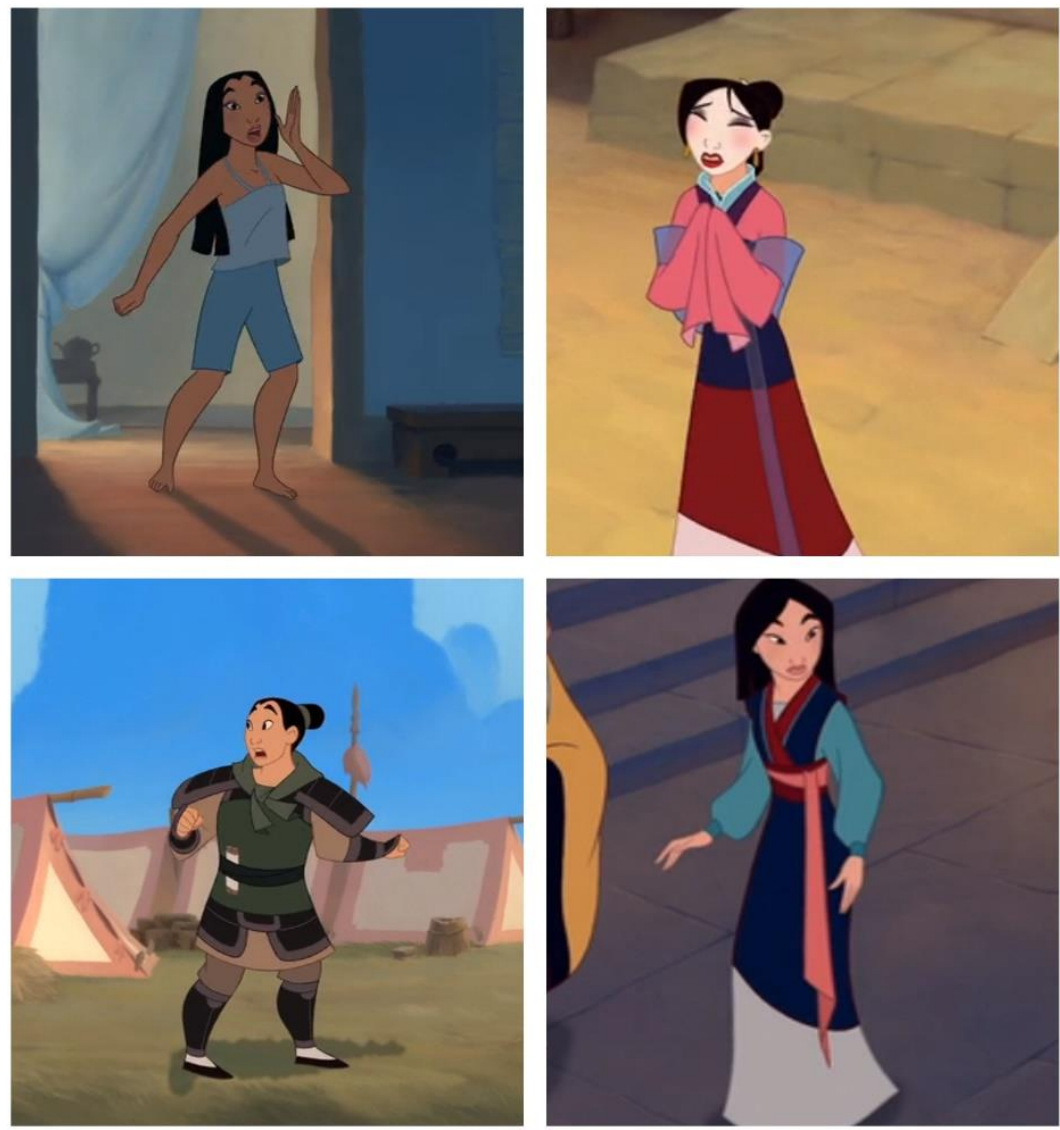

Fonte: Mulan (1998). À esquerda acima $4 \mathrm{ml}$ l6s, abaixo $31 \mathrm{~m} 36 \mathrm{~s}$, à direita acima $9 \mathrm{~m} 11 \mathrm{~s}$, abaixo $77 \mathrm{~m} 25 \mathrm{~s}$.

O filme Mulan nos traz elementos dignos de análise. Em primeiro lugar, o papel de "boa filha" desempenhado pela personagem principal ao vestir-se de homem e ir à guerra no lugar de seu pai. Em segundo lugar, na maior parte da narrativa, não há romance; a narrativa dá a entender o interesse de Mulan para com Shang e, posteriormente, de Shang para com Mulan, e que poderá ter um relacionamento não tradicional, mas muito feliz, possuindo respeito mútuo e entendimento (DAVIS, 2015, p. 198). Em terceiro lugar, a discussão pertinente durante a narrativa fílmica não é mais o romance, como foi em Branca de Neve, mas sim identidade e gênero (DAVIS, 2015, p. 199).

Mulan, ao longo da narrativa fílmica, procura estabelecer uma identidade própria diante das imposições sociais e seu querer, bem como procura honrar seu pai, ser uma boa filha sem deixar de cultivar suas 
BUENO, Lunielle de Brito Santos. A representação das mulheres e as discussões de gênero nas animações da Walt Disney. Domínios da Imagem, Londrina, v. 12, n. 23, p. 91-117, jul./dez. 2018.

qualidades, diferenciadas do "padrão" e alcança-a quando, sendo mulher, consegue lutar e mostrar suas melhores habilidades: coragem, inteligência e estratégia (DAVIS, 2015, p.198 e 199).

A narrativa fílmica de Mulan não apenas apresenta determinadas representações de feminilidade ou masculinidade, mas produzem e constroem tais representações (RAEL, 2018, p. 170). Consequentemente, afirmar os efeitos que tal construção e apresentação em seus espectadores é um terreno arenoso. Todavia, seguramente podemos afirmar que tais representações, de viver um tipo específico de masculinidade e feminilidade, tocam os imaginários de quem cresceu assistindo a tais animações (RAEL, 2018, p. 170).

\section{Considerações Finais}

Somos bombardeados, constantemente, por inúmeras construções narrativas com o intento de "nos constituir como sujeitos pertencentes a uma determinada identidade de gênero, de sexualidade, de classe, de etnia" (RAEL, 2018, p. 170). A partir disto, aprendemos a nos tornar sujeitos generificados desde a tenra infância a partir das investidas culturais, não só familiares, mas midiáticas, como as animações da Walt Disney.

Quando comparamos as esferas de análise historiográfica e a relação do micro com o macro na produção da Walt Disney Animation Studios, percebemos que muitas das mudanças das representações de mulheres têm relação não só com as mudanças dos agentes envolvidos, mas, principalmente, com uma demanda global de mercado.

Os avanços nas discussões feministas nos anos 1980 e os estudos historiográficos, antropológicos e sociológicos sobre gênero na época abriram as portas para uma nova leva de desenhistas, coloristas, produtoras e animadoras na produtora em questão. Isto posto, não só uma visão de papeis 
BUENO, Lunielle de Brito Santos. A representação das mulheres e as discussões de gênero nas animações da Walt Disney. Domínios da Imagem, Londrina, v. 12, n. 23, p. 91-117, jul./dez. 2018.

de mulheres tinha mudado, mas um modo de representar mulheres e a relação do público com as personagens mudaram drasticamente.

Ao compararmos as duas personagens, podemos perceber que Branca de Neve desempenha o papel de mulher passiva e Mulan o de boa filha. Apesar de ambos papeis serem problemáticos, quando refletimos sobre um certo "dever" a se cumprir, bastante naturalizado, quando nos afirmamos mulheres, a não passividade de Mulan, diante dos conflitos da narrativa, mostra-nos um olhar diferenciado sobre as discussões de gênero. Mulan comunica a mensagem de uma heroína que vai em busca de um ideal e que foge dos padrões, enquanto Branca de Neve conquista os homens ao seu redor pela sua passividade e virtude, causando inveja na antagonista, a Rainha.

Disso, segue-se que, em nenhum momento do filme Mulan, aparece uma vilã ou uma antagonista. Os vilões são hunos, todos homens; podemos elencar, inclusive, Chi-Fu como o antagonista, mas nenhuma mulher, mesmo a casamenteira, é colocada no enredo como uma figura extremamente negativa à heroína. Ademais, Mulan se apresenta com um certo "empoderamento feminino", de fazer o que quer, mesmo que seja encarado como uma ação "masculina". Entretanto, apesar de ser colocada como heroína da China, volta à esfera privada, junto de seu pai e familiares, não mostrando uma mudança radical na sociedade em que vive (DAVIS, 2015, p. 199).

A disputa clássica entre duas mulheres, uma jovem e uma madura, representada no enredo por Branca de Neve e a Rainha má, comunica-nos uma mensagem extremamente maléfica sobre relações de gênero entre mulheres: há uma competição, fruto da inveja, motivada pela beleza, podendo assim, tocar nos imaginários dos espectadores de que tal disputa deve ser naturalizada pois acontece em inúmeras circunstâncias.

Ainda sobre a comparação indireta entre as atitudes de Branca de Neve e da Rainha, podemos perceber uma mensagem, bastante tradicional 
BUENO, Lunielle de Brito Santos. A representação das mulheres e as discussões de gênero nas animações da Walt Disney. Domínios da Imagem, Londrina, v. 12, n. 23, p. 91-117, jul./dez. 2018.

de um pensamento patriarcal, de que a passividade leva a lugares altos, como os sonhos da princesa, e correr atrás dos seus sonhos desesperadamente te leva à ruína, como a morte da Rainha/Bruxa.

A fórmula das animações da Disney, quase sempre inspiradas em contos ou folclores tradicionais, quando colocados em foco o filme Branca de Neve e Mulan, pode ser dividida em duas grandes categorias: as passivas princesas resgatadas por um príncipe, como Branca de Neve, Cinderela e Aurora e as boas filhas, com um certo empoderamento contido, que buscam ajudar ou honrar seus pais, como Mulan, Bela e Tiana.

Mas se já é notável desde final da década de 80, com A Pequena Sereia (1989), a mudança de paradigma sobre a representação das mulheres, o ápice dessa mudança é marcado por Frozen (2013) e Moana (2016), filmes nos quais não há mais barreiras para o empoderamento das personagens e o romance é extremamente secundário ou inexistente, o que nos traz novos questionamentos do papel da mulher na esfera privada, mas, principalmente, pública e sócio-política.

\section{Referências}

AUMONT, J. O olho interminável: cinema e pintura. São Paulo: Cosac Naify Edições, 2004.

ALTMAN, R. Film/ Genre. London: Palgrave Macmillan, 1999.

BEAUVOIR, S. de. O segundo sexo. Volume II. Tradução Sérgio Milliet. Rio de Janeiro: Nova Fronteira, 1980.

BOURDIEU, P. Capital cultural, escuela y espacio social. Buenos Aires: Siglo xxi, 1997.

Branca de Neve e os Sete Anões. Direção: David Hand, William Cottrell, Wilfred Jackson, Larry Morey, Perce Pearce e Ben Sharpsteen. Produção: Walt Disney. Walt Disney Productions, 1937. 83 min, cor.

BUTLER, J.; TROUBLE, G. Feminism and the Subversion of Identity. New York: Roudledge, 1990. 
BUENO, Lunielle de Brito Santos. A representação das mulheres e as discussões de gênero nas animações da Walt Disney. Domínios da Imagem, Londrina, v. 12, n. 23, p. 91-117, jul./dez. 2018.

CHARTIER, R. A história cultural: entre práticas e representações. Trad. Maria Manuela Galhardo. Lisboa: Difusão Editora, 1988.

CHOLODENKO, A. (Ed.). The illusion of life: essays on animation. Sydney: University of Sydney, Power Institute of Fine Arts, 1991.

CONNELL, R.; PEARSE, R. Gênero: uma perspectiva global, tradução e revisão técnica de Marília Moschkovich. São Paulo: nVersos, 2015.

DAVIS, A. M. Good Girls \& Wicked Witches: Women in Disney's Feature Animation. 3. ed. New Barnet, United Kingdom: John Libbey Publishing, 2015.

DENIS, S. O cinema de animação. Lisboa, Portugal: Edições Texto \& Grafia, 2010.

DIDI-HUBERMAN, G. Que emoção! Que emoção? Tradução de Cecília Ciscato. São Paulo: Editora 34, 2016.

EISENSTEIN, S. Eisenstein on Disney. Kolkata, India: Seagull Books Pvt Ltd, 1986. GUINNESS World Records 2018. New York: HarperCollins Publishers, 2018. KARAWEJCZYK, M. As suffragettes e a luta pelo voto feminino. História, imagem e narrativas, n. 17, out. 2013.

MACHADO, A. A ilusão especular: introdução à fotografia. São Paulo: Brasiliense/Funarte, 1984.

MANOVICH, L. 'Reality'effects in computer animation. In: PILLING, J. (Org.). A reader in animation studies. Londres: John Liberty, 1997. p. 5-15.

MARTIN, A. Écrits sur l'animation, 1. Apresentado e comentado por CLARENS, B. Paris: Dreamland, 2000.

MOINS, P. Les Maîtres de la pâte. Paris: Dreamland, 2001.

MORETTIN, E. O cinema como fonte histórica na obra de Marc Ferro. In: História e Cinema. São Paulo: Alameda, 2007.

Mulan. Direção: Tony Bancroft e Barry Cook. Produção: Pam Coats. Walt Disney Pictures, 1998. 87 min, cor.

NAPOLITANO, M. A história depois do papel. In: PINSKY, C. B. (Org). Fontes Históricas. 2. ed. São Paulo: Contexto, 2008. p. 235-290.

OLIVEIRA, D. O cinema como fonte para a história. In: Fontes históricas: métodos e tipologias, III Evento de Extensão em Pesquisa Histórica, Curitiba, Anais do III Evento de Extensão em Pesquisa Histórica, Curitiba: UFPR, 2008. p. $1-12$. 
BUENO, Lunielle de Brito Santos. A representação das mulheres e as discussões de gênero nas animações da Walt Disney. Domínios da Imagem, Londrina, v. 12, n. 23, p. 91-117, jul./dez. 2018.

PISCITELLI, A. Gênero: a história de um conceito, In: ALMEIDA, H. B.; SZWACO, J. E. (Orgs.). Diferenças, Igualdade. São Paulo: Berlendis \& Vertecchia, 2009. p.116-149. Re-criando a (categoria) mulher? Textos didáticos, v. 48, p. 7-42, 2002.

RAEL, C.C. Gênero e sexualidade nos desenhos da Disney. In: LOURO, G.L.; FELIPE, J.; GOELLNER, S.V. (Orgs.). Corpo, gênero e sexualidade: um debate contemporâneo na educação. 9. ed. Petrópolis: Vozes, 2018. p.160-171.

SCOTT, J. História das Mulheres. In: BURKE, P. (Org.). A Escrita da história: novas perspectivas. Tradução de Magda Lopes. São Paulo: UNESP, 1992. p. 63-96. 